\title{
Expression patterns of nestin and dentin sialoprotein during dentinogenesis in mice
}

\author{
Angela Quispe-Salcedo, Hiroko IdA-Yonemochi, Mitsushiro NaKatomi, and Hayato Ohshima \\ Division of Anatomy and Cell Biology of the Hard Tissue, Department of Tissue Regeneration and Reconstruction, Niigata University \\ Graduate School of Medical and Dental Sciences, 2-5274 Gakkocho-dori, Chuo-ku, Niigata 951-8514, Japan
}

(Received 7 January 2012; and accepted 8 February 2012)

\begin{abstract}
Differentiated odontoblasts could not be identified by one unique phenotypic marker, but the combination of expression of dentin phosphoprotein (Dpp), dentin sialoprotein (Dsp), dentin matrix protein 1 (Dmp1), and nestin may be valuable for the assessment of these cells. However, the findings using these proteins remain controversial. This study aimed to compare two odontoblast differentiation markers: nestin and Dsp in the process of dentinogenesis in mice. We performed immunohistochemistry and/or in situ hybridization technique for nestin and Dsp using 3-week-old incisors as well as postnatal 1-day- to 8-week-old molars. Preodontoblasts began to express nestin and Dsp proteins and Dsp mRNA, which increased in their intensity according to the progress of odontoblast differentiation in both incisors and developing molars. Nestin was consistently expressed in the differentiated odontoblasts even after the completion of dentin matrix deposition. The expression of Dsp mRNA coincided with the odontoblast secretory activity for dentin matrix deposition. In contrast, other pulpal cells, predentin matrix and dentinal tubules also showed a positive reaction for Dsp protein in addition to differentiated odontoblasts. In conclusion, nestin is valuable as a differentiation marker for odontoblasts, whereas Dsp mRNA is a functional marker for their secretory activity.
\end{abstract}

Dentin is a hard connective tissue that forms the bulk of the tooth, and it is a bone-like matrix characterized by multiple closely packed dentinal tubules that traverse its entire thickness and contain the cytoplasmic processes of odontoblasts, which are responsible for the formation and maintenance of the dentin. The cell bodies of the odontoblasts are aligned along the inner aspect of the dentin, beneath a layer of predentin, where they also form the peripheral boundary of the dental pulp (35). The

Address correspondence to: Hayato Ohshima, DDS, PhD Division of Anatomy and Cell Biology of the Hard Tissue, Department of Tissue Regeneration and Reconstruction, Niigata University Graduate School of Medical and Dental Sciences, 2-5274 Gakkocho-dori, Chuo-ku, Niigata 951-8514, Japan

Tel: +81-25-227-2812, Fax: +81-25-227-0804

E-mail: histoman@dent.niigata-u.ac.jp odontoblasts are terminally differentiated ectomesenchymal cells that synthesize several collagenous and non-collagenous proteins (NCPs) (45). The morphologically discernible differentiation of the odontoblast begins with the dental papilla cells adjacent to the inner enamel epithelium (7). The dental papilla cells adjoining the acellular zone rapidly enlarge and elongate to become preodontoblasts first and then odontoblasts as their cytoplasm increases in volume to contain increasing amounts of proteinsynthesizing organelles. The morphology of odontoblasts reflects their functional activity and ranges from an active synthetic phase to a quiescent phase (35). However, the preferred use of terminology regarding the classification of odontoblasts is controversial, because several terms for differentiated odontoblasts have been used by different researchers, i.e., secretory, transitional, and aged odontoblasts (12), young and old odontoblasts (51), or 
immature and mature odontoblasts (39).

Rodent incisors are continuously growing teeth, for which all stages of odontogenesis-including amelogenesis and dentinogenesis - can be surveyed if the sections of the tooth are prepared from the apical end to the incisal edge $(39,48)$. Recent molecular biological studies have demonstrated the existence of a niche for self-renewing adult stem cells in these rodent incisors, which is referred to as an "apical bud" (21-23, 40, 56). Thus, continuously growing incisors are useful materials for analyzing the developmental process of dentinogenesis, although the incisal edge shows the unique feature that an inflammatory reaction is induced by the attrition of the incisal tip (39). In contrast, rodent molars are teeth with limited growth similar to human teeth. The rate of dentin deposition increases in the early stage of coronal dentin formation and subsequently almost ceases, suggesting the transition from the active to quiescent stages of secretory odontoblasts (57). Hence, both rodent incisor and molar teeth should be compared for the exact understanding of dentinogenesis.

The selection of odontoblast differentiation markers is important for the proper assessment of the differentiation process of odontoblasts. Among these markers, NCPs have been widely studied, especially the small integrin binding ligand, N-linked glycoprotein (SIBLING) family, which is composed of dentin sialophosphoprotein (Dspp), dentin matrix protein 1 (Dmp1), osteopontin (Opn), bone sialoprotein (Bsp), and matrix extracellular phosphoglycoprotein (Mepe) (16). Dspp is proteolytically cleaved into dentin sialoprotein (Dsp) and dentin phosphoprotein (Dpp) $(49,55)$. However, differentiated odontoblasts could not be identified by a unique phenotypic marker; a combination of markers such as Dsp, Dpp, Dmp1, and nestin has been applied to identify these cells (18). Dspp and/or its cleaved products Dsp and Dpp are believed to be tooth-specific (11), although they are also expressed in preameloblasts (6, 8, 10, 15, 43, 44). Recent studies have shown the expression of Dspp in bone (41, 42), cementum (3), and some non-mineralized tissues $(2,37,38)$, while its expression in non-dental tissues is lower than that in dentin. Dmp1 is an acidic phosphoprotein predominantly expressed in dentin, bone, and cementum $(17,30)$. A lower level of expression for these proteins has also been found in non-mineralized tissues such as the brain, kidney, pancreas, and salivary gland (53). Among them, the intermediate filament nestin is considered as a marker for differentiated odontoblasts in developing teeth and newly-differentiated odontoblast-like cells ap-

Table 1 Comparison of nestin and dentin sialoprotein (Dsp) immunoreactivity and Dsp mRNA expression during dentinogenesis in a 3-week-old incisor

\begin{tabular}{|c|c|c|c|c|c|}
\hline & \multirow[b]{2}{*}{ apical bud } & \multirow[b]{2}{*}{ dental papilla } & \multirow[b]{2}{*}{ preodontoblasts } & \multicolumn{2}{|c|}{ odontoblasts } \\
\hline & & & & immature & mature \\
\hline nestin & $+/-$ & - & + & ++ & +++ \\
\hline Dsp & + & - & $+1-$ & ++ & +++ \\
\hline Dsp mRNA & - & - & $+/-$ & ++ & +++ \\
\hline
\end{tabular}

-: negative, + /-: very weak, +: weakly positive, ++ : medium positive, +++ : intensely positive

Fig. 1 Expression of nestin (a, $\mathbf{d}, \mathbf{g}, \mathbf{j}, \mathbf{m}, \mathbf{p})$ and Dsp proteins (b, e, h, $\mathbf{k}, \mathbf{n}, \mathbf{q})$, and Dsp mRNA (c, $\mathbf{f}, \mathbf{I}, \mathbf{I}, \mathbf{o}, \mathbf{r})$ in a 3 week-old incisor. Figs. $\mathbf{d}, \mathbf{g}, \mathbf{j}, \mathbf{m}$, and $\mathbf{p}$ are higher magnified views of the boxed areas in $\mathbf{a}$. Figs. $\mathbf{e , ~} \mathbf{h}, \mathbf{k}, \mathbf{n}$, and $\mathbf{q}$ are higher magnified views of the boxed areas in $\mathbf{b}$. Figs. $\mathbf{f}, \mathbf{i}, \mathbf{I}, \mathbf{0}$, and $\mathbf{r}$ are higher magnified views of the boxed areas in $\mathbf{c}$. Nestin and Dsp proteins are intensely expressed in odontoblasts, although other pulpal cells also show weak positive reactions (a, b). The expression of Dsp mRNA coincides with the odontoblast secretory activity for dentin matrix deposition (c). Faint positive reactions for nestin and Dsp are observed in the dental papilla and follicle around the apical bud, respectively (d, e), whereas there is no Dsp mRNA in this area (f). Nestin is expressed in preodontoblasts and immature odontoblasts, and the apical end of their cytoplasm begins to show intense immunoreactions according to the progress of odontoblast differentiation (j, m). Finally, mature odontoblasts show intense immunoreactions in their entire cytoplasm including their cellular processes (p). Stellate reticulum also shows faint immunoreactions for nestin (g). Intense Dsp immunoreactions are localized in the Golgi area of immature and mature odontoblasts as well as other pulpal cells (k, $\mathbf{n}$, q). Dentinal tubules and predentin matrix also show positive reactions for Dsp (q) in addition to preameloblasts, ameloblasts, and stellate reticulum ( $\mathbf{h}, \mathbf{k}, \mathbf{n})$. Preodontoblasts begin to express Dsp mRNA and increase in their intensity according to the progress of odontoblast differentiation (i, I, o), and finally mature odontoblasts intensely express Dsp mRNA in their cytoplasm (r). Arrows: enamel matrix, arrowheads: odontoblastic capillaries, AB: ameloblasts, B: bone, D: dentin, DP: dental pulp, E: enamel, IEE: inner enamel epithelium, iOB: immature odontoblasts, mOB: mature odontoblasts, pAB: preameloblasts, PD: predentin, pOB: preodontoblasts, SR: stellate reticulum Bars $500 \mu \mathrm{m}(\mathrm{a}-\mathrm{c}), 50 \mu \mathrm{m}(\mathrm{d}-\mathrm{f}), 25 \mu \mathrm{m}(\mathrm{g}-\mathrm{r})$ 

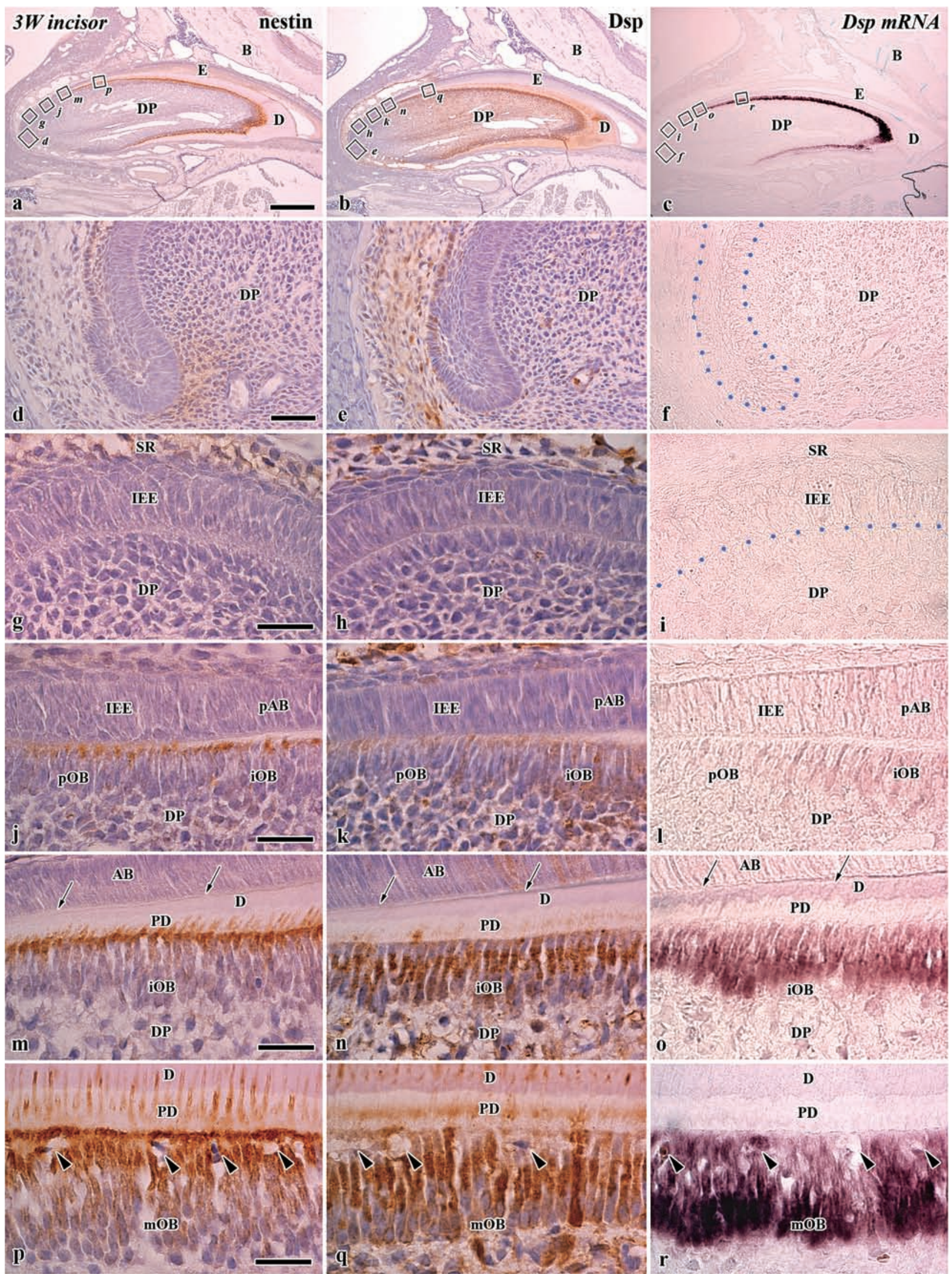

Fig. 1 
pearing following tooth injuries such as cavity preparation and tooth replantation/transplantation (1, 24, $26,28,36,46,54)$. Regarding immunohistochemistry for Dmp1, we failed to obtain a specific immunoreaction in the differentiated odontoblasts in our preliminary experiments (data not shown). Thus, this study aimed to compare two odontoblast differentiation markers: nestin and Dsp in the process of dentinogenesis in mice, using immunohistochemistry and/or in situ hybridization technique for nestin and Dsp in 3-week-old incisors as well as postnatal 1-day- to 8-week-old molars.

\section{MATERIALS AND METHODS}

Tissue preparation. All experiments were reviewed by the Committee on the Guidelines for Animal Experimentation of Niigata University and performed according to the recommendations or under the conditions proposed by the committee. Materials were collected in groups of 2 to 5 ICR mice at intervals of $1(n=3), 3(n=2), 5(n=2), 7$ days $(n=3)$ and $3(n=5), 5(n=3)$ and 8 weeks $(n=2)$ after birth. At each stage, the animals were perfused with physiological saline transcardially followed by $4 \%$ paraformaldehyde in a $0.1 \mathrm{M}$ phosphate buffer $(\mathrm{pH} 7.4)$ under deep anesthesia by an intraperitoneal injection of chloral hydrate (the maximum dose of $350 \mathrm{mg} /$ $\mathrm{kg}$ ). The maxillae were removed en bloc and immersed in the same fixative for an additional $12 \mathrm{~h}$ at $4^{\circ} \mathrm{C}$. Following decalcification in Morse's solution ( $10 \%$ sodium citrate and $22.5 \%$ formic acid) (47) for 1-4 days at $4^{\circ} \mathrm{C}$, the specimens were dehydrated through ethanol series and embedded in paraffin, and sagittal sections of maxillae were cut at $4 \mu \mathrm{m}$. The paraffin sections were mounted on Matsunami adhesive silane (MAS)-coated glass slides (Matsunami Glass Ind., Osaka, Japan) and stained with H\&E.

Immunohistochemical analysis. For the immuno-per- oxidase procedure, the sections were processed for the EnVision method (DAKO Japan, Tokyo, Japan) using a mouse anti-nestin monoclonal antibody diluted $1: 100$ (Millipore, Temecula, CA, USA) and the avidin-biotin peroxidase complex (Vectastain ABC kit; Vector Laboratories Inc., Burlingame, CA, USA) method using goat anti-Dsp polyclonal antibody diluted $1: 50$ or $1: 500$ (Santa Cruz Biotechnology, Inc., CA, USA), since the previous reports used the different dilutions of anti-Dsp antibody and we had to confirm the suitable concentration. The sections were counter-stained with hematoxylin. Immunohistochemical controls were performed by replacing the primary antibodies with PBS. These immunostained sections contained no specific immunoreaction.

For double immunofluorescent staining for nestin and Dsp, frozen sections ( $40 \mu \mathrm{m}$ in thickness) from 3 -week-old incisors were treated by three consecutive incubations with a mouse anti-nestin monoclonal antibody diluted 1:50 (Millipore), biotinylated anti-mouse IgG diluted 1:100 (Vector), and FITCconjugated streptavidin diluted $1: 250$ (Vector). After washing with PBS and blocking with Avidin/Biotin Blocking kit (Vector), they were then consecutively incubated with goat anti-Dsp polyclonal antibody diluted $1: 25$, biotinylated anti-goat IgG (Vector), and Texas red-conjugated streptavidin diluted $1: 100$ (Vector). The sections were examined with a confocal laser scanning microscope (FV300; Olympus, Tokyo, Japan).

In situ hybridization. Tissue section in situ hybridization was conducted as previously described (34). A digoxigenin-labeled probe for Dsp mRNA (43) was prepared according to the manufacturer's protocol. Following the fixation, the specimens were decalcified with Morse's solution (10\% sodium citrate and $22.5 \%$ formic acid) for $24 \mathrm{~h}(47)$, dehydrated through ethanol series and xylene, and embedded in

Fig. 2 Expression of both nestin and Dsp (a, d, g, j, $\mathbf{m})$, Dsp (b, e, h, $\mathbf{k}, \mathbf{n})$, and nestin (c, f, i, I, o) in a 3 week-old incisor. Second and third rows are differently sliced views in the same section as well as fourth and fifth rows. The first row is the position including preodontoblasts, immature odontoblasts, and inner enamel epithelium. The second row is the position including immature odontoblasts and preameloblasts. The fourth row is the position including mature odontoblasts. The first row is near and the fourth and fifth rows are far from the apical bud, whereas the second and third rows are the positions between them. Nestin and Dsp are expressed in preodontoblasts and immature odontoblasts (a-f), and the apical end of their cytoplasm begins to show intense immunoreactions for nestin according to the progress of odontoblast differentiation $(\mathbf{g}, \mathbf{i})$. Finally, mature odontoblasts contain intense immunoreactions for nestin in their entire cytoplasm including their cellular processes $(\mathbf{j}, \mathbf{m}, \mathbf{I}, \mathbf{o})$. Stellate reticulum and stratum intermedium also show faint immunoreactions for nestin and Dsp $(\mathbf{a}-\mathbf{f})$. Intense Dsp immunoreactions are localized in the Golgi area of immature and mature odontoblasts (d, e, j, k). Predentin matrix and dentinal tubules also show positive reactions for $\operatorname{Dsp}(\mathbf{g}, \mathbf{h}, \mathbf{m}, \mathbf{n})$ in addition to preameloblasts (d, e). D: dentin, DP: dental pulp, IEE: inner enamel epithelium, iOB: immature odontoblasts, mOB: mature odontoblasts, pAB: preameloblasts, PD: predentin, pOB: preodontoblasts, SI: stratum intermedium, SR: stellate reticulum Bar $100 \mu \mathrm{m}$. 


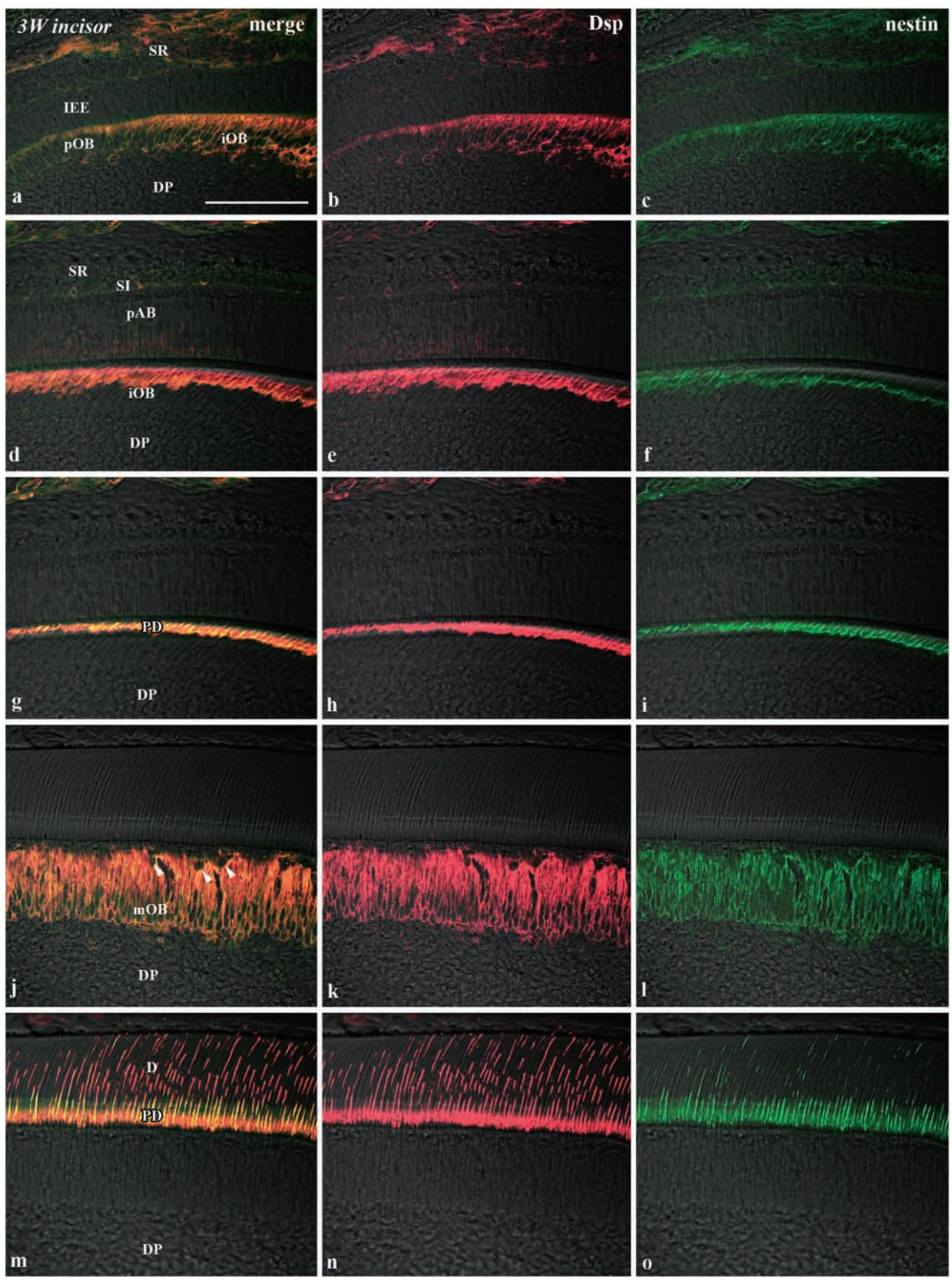

Fig. 2 
paraffin. Five- $\mu$ m-thick paraffin sections were mounted on MAS-coated glass slides, deparaffinized, dehydrated, and predigested with proteinase $\mathrm{K}$. The sections were then acetylated with $0.25 \%$ acetic anhydride in triethanolamine for $10 \mathrm{~min}$ and incubated overnight at $70^{\circ} \mathrm{C}$ with hybridization buffer containing a digoxigenin-labeled probe for Dsp mRNA. After hybridization, the slides were washed in a series of sodium citrate-sodium chloride solution and treated by two consecutive incubations with blocking reagent (Roche Diagnostics Corp., Indianapolis, IN, USA) and anti-digoxigenin antibody (Roche). The sections were stained with 4-nitro-blue tetrazolium/ 5-bromo-4-chloro-3-indolyl phosphate (Roche).

\section{RESULTS}

\section{Incisor at Week 3 (Table 1)}

Nestin and Dsp were intensely expressed in odontoblasts, although other pulpal cells also showed weak positive reactions (Fig. 1a, b). The expression of Dsp mRNA coincided with the odontoblast secretory activity for dentin matrix deposition (Fig. 1c). Faint positive reactions of nestin and Dsp were observed in the dental papilla and follicle around an apical bud, respectively (Fig. 1d, e). Nestin was expressed in preodontoblasts and immature odontoblasts, and the apical end of their cytoplasm began to show intense immunoreactions according to the progress of odontoblast differentiation (Fig. 1j, m). Finally, ma- ture odontoblasts contained intense immunoreaction in their entire cytoplasm including their cellular processes (Fig. 1p). Stellate reticulum in the enamel organ also showed faint immunoreaction for nestin (Fig. 1g). Intense Dsp immunoreactions were localized in the Golgi area of immature and mature odontoblasts as well as other pulpal cells (Fig. 1k, n, q). Dentinal tubules and predentin matrix also showed positive reactions for Dsp (Fig. 1q) in addition to stellate reticulum (Fig. 1h, k). Preodontoblasts began to express Dsp mRNA and increased their intensity according to the progress of odontoblast differentiation (Fig. 1l, o), and finally mature odontoblasts showed intense expression of Dsp mRNA in their cytoplasm (Fig. 1r).

\section{Double immunofluorescent staining in incisor at Week 3}

Nestin and Dsp were expressed in preodontoblasts and immature odontoblasts (Fig. 2a-f), and the apical end of their cytoplasm began to show intense immunoreactions for nestin according to the progress of odontoblast differentiation (Fig. 2a, c, d, f). Finally, mature odontoblasts contained intense immunoreactions for nestin in their entire cytoplasm including their cellular processes (Fig. 2j, m, l, o). Stellate reticulum and stratum intermedium also showed faint immunoreactions for nestin and Dsp (Fig. 2a-f). Intense Dsp immunoreactions were localized in the Golgi area of immature and mature

Table 2 Comparison of nestin and Dsp immunoreactivity and Dsp mRNA expression during dentinogenesis in developing molars

\begin{tabular}{|c|c|c|c|c|c|c|c|c|c|c|c|c|c|c|c|}
\hline & \multicolumn{3}{|c|}{ Day 1} & \multicolumn{3}{|c|}{ Week 1} & \multicolumn{3}{|c|}{ Week 3} & \multicolumn{3}{|c|}{ Week 5} & \multicolumn{3}{|c|}{ Week 8} \\
\hline & \multirow[t]{2}{*}{$\mathrm{DP}$} & \multicolumn{2}{|c|}{$\mathrm{OB}$} & \multirow[t]{2}{*}{$\mathrm{DP}$} & \multicolumn{2}{|c|}{$\mathrm{OB}$} & \multirow[t]{2}{*}{$\mathrm{DP}$} & \multicolumn{2}{|c|}{ OB } & \multirow[t]{2}{*}{$\mathrm{DP}$} & \multicolumn{2}{|c|}{ OB } & \multirow[t]{2}{*}{$\mathrm{DP}$} & \multicolumn{2}{|c|}{$\mathrm{OB}$} \\
\hline & & $\mathrm{C}$ & $\mathrm{R}$ & & $\mathrm{C}$ & $\mathrm{R}$ & & $\mathrm{C}$ & $\mathrm{R}$ & & $\mathrm{C}$ & $\mathrm{R}$ & & $\mathrm{C}$ & $\mathrm{R}$ \\
\hline nestin & - & + & N/A & - & ++ & + & $+/-$ & +++ & ++ & - & ++ & ++ & - & ++ & ++ \\
\hline Dsp & + & + & N/A & + & ++ & + & ++ & +++ & ++ & +++ & +++ & +++ & +++ & +++ & +++ \\
\hline Dsp mRNA & $+/-$ & ++ & N/A & $+1-$ & +++ & ++ & $+1-$ & +++ & ++ & $+1-$ & + & + & - & $+/-$ & - \\
\hline
\end{tabular}

-: negative, +/-: very weak, +: weakly positive, ++ : medium positive, +++ : intensely positive, N/A: not available

C: coronal dentin, DP: dental pulp, OB: odontoblasts, R: root dentin

Fig. 3 Expression of nestin (a, d, $\mathbf{g}, \mathbf{j}, \mathbf{m})$ and Dsp proteins (b, e, h, $\mathbf{k}, \mathbf{n})$ and Dsp mRNA (c, f, i, I, o) in a 1 day-old molar. Figs. $\mathbf{d}$, e and $\mathbf{f}$ are higher magnified views of cervical areas of Figs. $\mathbf{a}, \mathbf{b}$, and $\mathbf{c}$, respectively. Figs. $\mathbf{g}$, j, and $\mathbf{m}$ are higher magnified views of the boxed areas in $\mathbf{a}$. Figs. $\mathbf{h}, \mathbf{k}$, and $\mathbf{n}$ are higher magnified views of the boxed areas in $\mathbf{b}$. Figs. $\mathbf{i}$, $\mathbf{I}$, and $\mathbf{o}$ are higher magnified views of the boxed areas in c. Odontoblasts consistently express nestin and Dsp proteins and Dsp mRNA (a-c). Other pulpal cells show positive reaction for Dsp protein as well as bone cells $(\mathbf{b}, \mathbf{e}, \mathbf{h}, \mathbf{k}, \mathbf{n})$. Intense expression of Dsp mRNA is observed in the part of the enamel organ (c). Preodontoblasts begin to express nestin and Dsp proteins and Dsp mRNA (d-i), and increase their intensity according to the progress of odontoblasts differentiation (j-o). Preameloblasts also show immunoreactions for Dsp protein and Dsp mRNA (k, I), and positive reaction for only Dsp protein is observed in the dentinal tubules (n). Arrows: enamel matrix, AB: ameloblasts, B: bone, D: dentin, DP: dental pulp, EO: enamel organ, IEE: inner enamel epithelium, iOB: immature odontoblasts, pAB: preameloblasts, PD: predentin, pOB: preodontoblasts Bars $500 \mu \mathrm{m}(\mathrm{a}-\mathrm{c}), 50 \mu \mathrm{m}(\mathrm{d}-\mathrm{f}), 25 \mu \mathrm{m}(\mathrm{g}-\mathrm{o})$. 


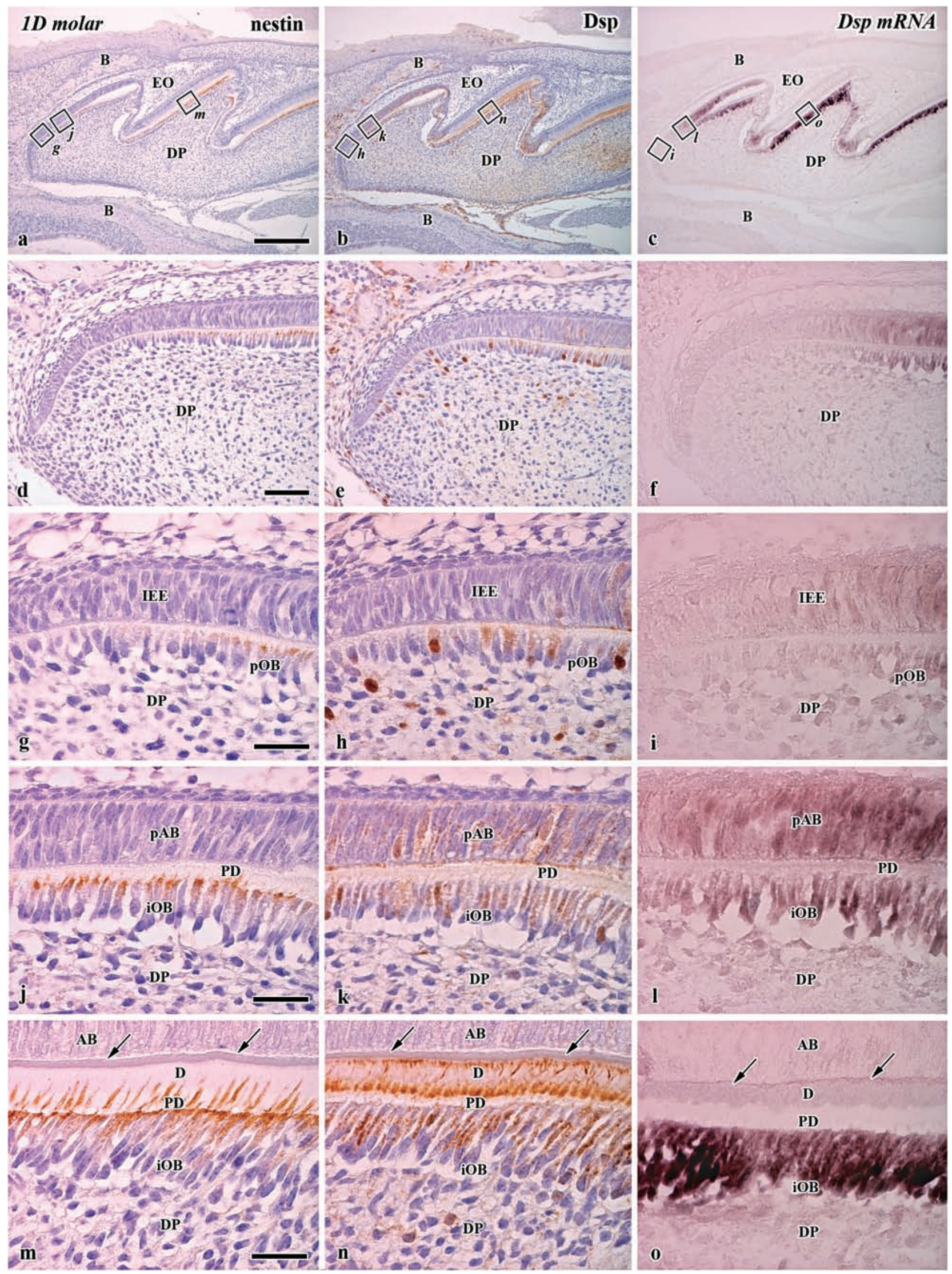

Fig. 3 
odontoblasts (Fig. 2d, e, j, k). Dentinal tubules and predentin matrix also showed positive reactions for Dsp (Fig. 2g, h, m, n) in addition to preameloblasts (Fig. 2d, e).

\section{Molar at Day 1 (Table 2)}

Odontoblasts consistently expressed nestin and Dsp proteins and Dsp mRNA (Fig. 3a-c). Other pulpal cells showed positive reaction for Dsp protein as well as bone cells (Fig. 3b, e, h, k, n). Intense expression of Dsp mRNA was observed in the part of the enamel organ (Fig. 3c). Preodontoblasts began to express nestin and Dsp proteins and Dsp mRNA (Fig. 3d-i), which increased their intensity according to the progress of odontoblast differentiation (Fig. 3jo). Preameloblasts also showed immunoreaction for Dsp protein and expressed Dsp mRNA (Fig. 3k, l), and positive reaction for only Dsp protein was observed in the dentinal tubules (Fig. 3n).

\section{Molar at Week 1 (Table 2)}

Odontoblasts consistently expressed nestin and Dsp proteins and Dsp mRNA (Fig. 4a-c). Other pulpal cells showed a positive reaction for Dsp protein as well as bone cells (Fig. 4b, e, h, k). Dentinal tubules and predentin matrix in the coronal dentin showed intense expression of Dsp protein (Fig. 4k). Immature and mature odontoblasts expressed intense nestin and Dsp proteins and Dsp mRNA in their cytoplasm (Fig. 4g-l).

\section{Molar at Week 3 (Table 2)}

Root formation progressed at this stage when odontoblasts continued to express nestin and Dsp proteins and Dsp mRNA (data not shown). Nestin immunoreactivity in the odontoblast cell processes in the predentin of coronal dentin was more intense than that in the root and pulp floor dentin, and this tendency continued until Week 5. Other pulpal cells and dentinal tubules showed intense positive reaction for Dsp protein (data not shown).
Molar at Weeks 5 and 8 (Table 2)

We adopted two different concentrations (1:50 and 1:500) for Dsp immunohistochemistry. The Dsp immunoreaction increased in intensity according to the progress of dentinogenesis and the use of different dilution of antibody was recommended to get the suitable stainability in dentin-pulp complex at each stage. Odontoblasts consistently expressed nestin and Dsp proteins during Weeks 5-8 (Fig. 5a-f), although the expression of Dsp mRNA in the odontoblasts became weak in intensity at Week 5 (data not shown) and almost disappeared except for some odontoblasts beneath the enamel-free area (9) and in the pulpal floor at Week 8 (Fig. 5g, h, i, k). Increased immunoreaction for Dsp protein was recognized in the coronal dentinal tubules and dental pulp according to aging (Fig. 5c, d), and intense expression of Dsp mRNA appeared in some cementoblasts at Week 8 (Figs. 5j, l).

\section{DISCUSSION}

\section{Dsp}

The present study clearly demonstrated that the expression of Dsp mRNA coincided with the odontoblast secretory activity for dentin matrix deposition in both 3-week-old incisors and developing molars, judging from the previous data: the rate of dentin deposition in the medial coronal portion almost ceases after 60 days in rats (57) and the progress of dentinogenesis in mice is faster than that in rats (26, 27). In contrast, other pulpal cells, predentin matrix and dentinal tubules showed positive reactions only for Dsp protein and increased in their intensity according to the progress of tooth development. Previous in situ hybridization experiments showed that Dsp and Dspp mRNA were expressed only by odontoblasts and not by other cell types except for preameloblasts in the mouse incisor and molar at Day 11 (43) or developing rat incisors and molars during embryonic day 20 to postnatal day $20(4,19)$ and developing mouse molars during Day 1 to Week 8 $(5,58)$. These observations are consistent with the

Fig. 4 Expression of nestin (a, d, $\mathbf{g}, \mathbf{j})$ and Dsp proteins (b, e, h, $\mathbf{k})$ and Dsp mRNA (c, $\mathbf{f}, \mathbf{i}, \mathbf{I})$ in a 1 week-old molar. Figs. $\mathbf{d}$, e, and $\mathbf{f}$ are higher magnified views of cervical areas of Figs. $\mathbf{a}, \mathbf{b}$, and $\mathbf{c}$, respectively. Figs. $\mathbf{g}$ and $\mathbf{j}$ are higher magnified views of the boxed areas in $\mathbf{a}$. Figs. $\mathbf{h}$ and $\mathbf{k}$ are higher magnified views of the boxed areas in $\mathbf{b}$. Figs. $\mathbf{i}$ and $\mathbf{I}$ are higher magnified views of the boxed areas in c. Odontoblasts consistently express nestin and Dsp proteins, and Dsp mRNA (ac). Other pulpal cells show positive reaction for Dsp protein as well as bone cells (b, e, $\mathbf{h}, \mathbf{k})$. Dentinal tubules in the coronal dentin show intense expression of Dsp protein (k). Immature and mature odontoblasts express intense nestin and Dsp proteins and Dsp mRNA in their cytoplasm (d-I). Arrowheads: odontoblastic capillaries, AB: ameloblasts, B: bone, D: dentin, DP: dental pulp, E: enamel, EO: enamel organ, iOB: immature odontoblasts, mOB: mature odontoblasts, pAB: preameloblasts, PD: predentin Bars $250 \mu \mathrm{m}(\mathrm{a}-\mathrm{c}), 50 \mu \mathrm{m}(\mathrm{d}-\mathrm{f}), 25 \mu \mathrm{m}(\mathrm{g}-\mathrm{l})$ 

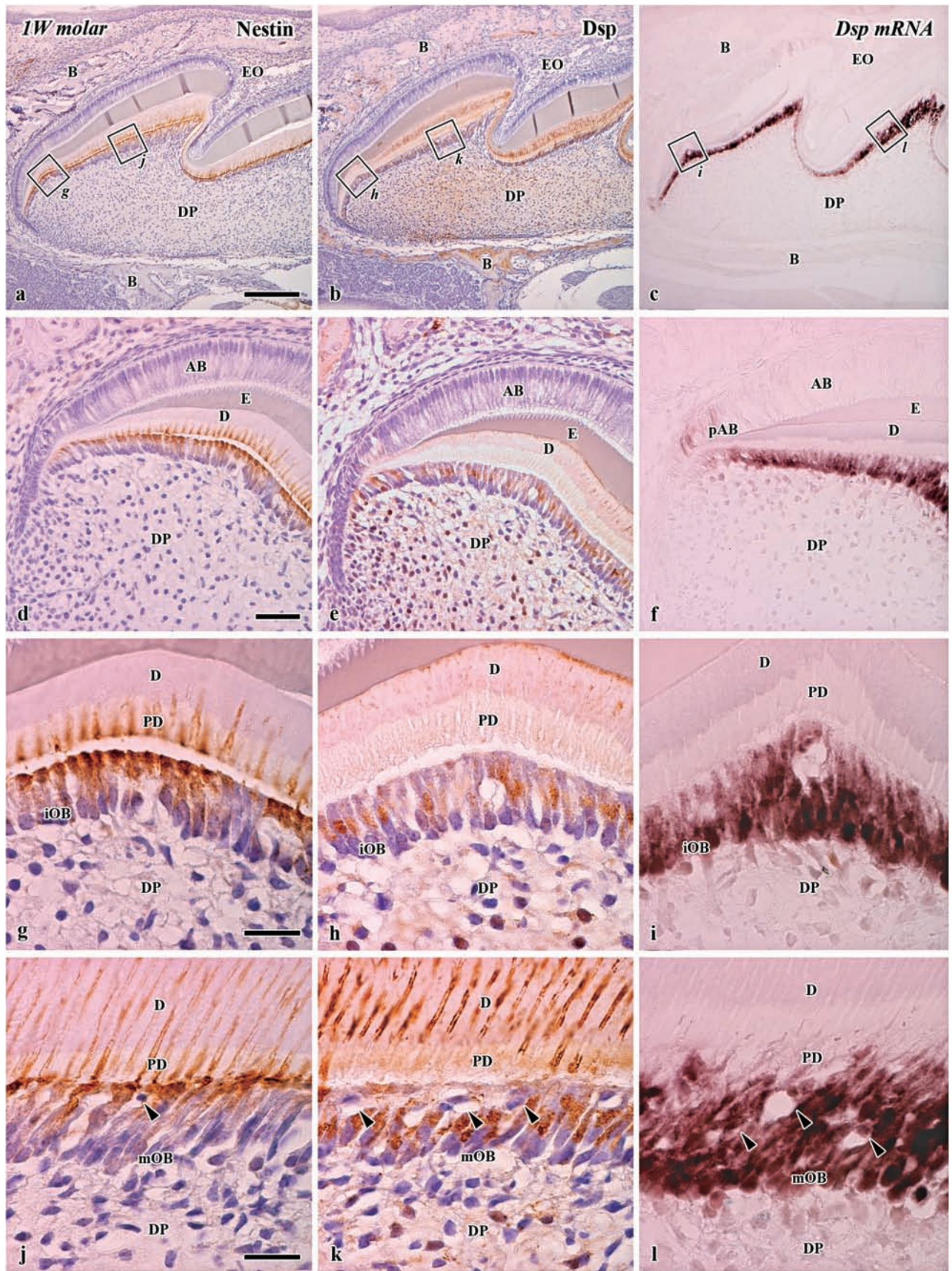

AB
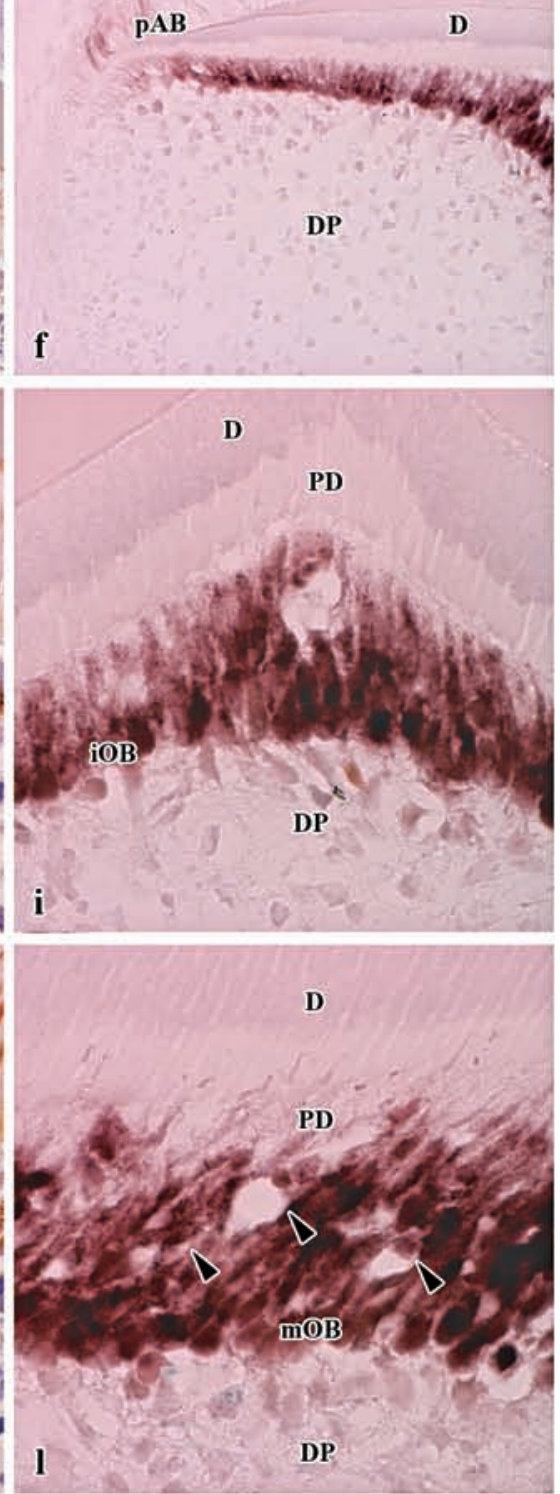

Fig. 4 

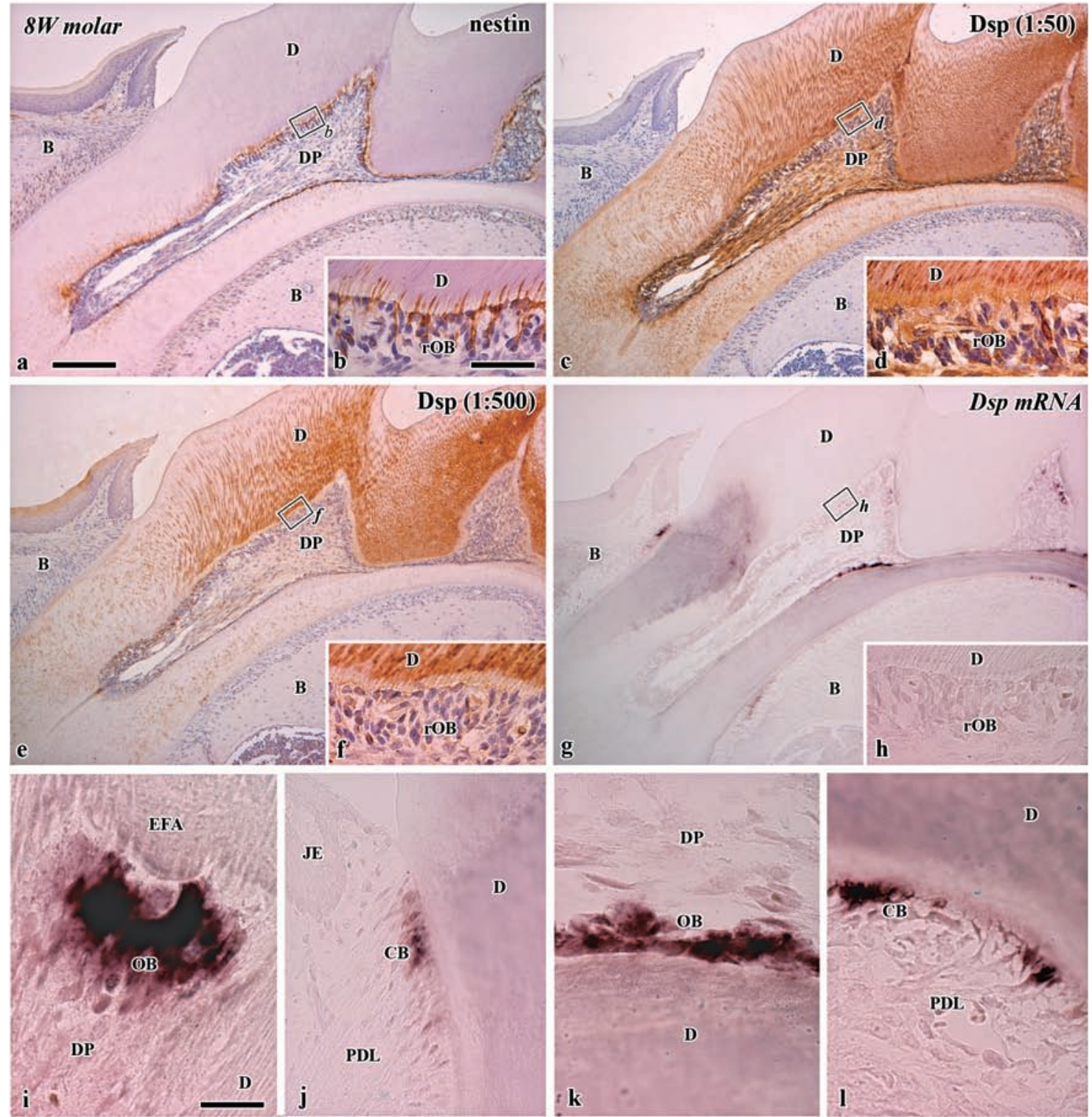

Fig. 5 Expression of nestin (a, b) and Dsp proteins (c, d, e, f) and Dsp mRNA (g-l) in an 8 week-old molar. Figs. b, d, f, and $\mathbf{h}$ are higher magnified views of the boxed areas in $\mathbf{a}, \mathbf{c}, \mathbf{e}$, and $\mathbf{g}$, respectively. Odontoblasts consistently express nestin protein (a) and Dsp protein which is demonstrated at two different antibody concentrations, 1:50 (c) and 1:500 (e). The Dsp immunoreaction increases in intensity according to the progress of dentinogenesis and the use of different dilution of antibody produces the suitable stainability in dentin-pulp complex at each stage. The expression of Dsp mRNA almost disappears (g) except for some odontoblasts beneath the enamel-free area (EFA) (i) and in the pulpal floor (k). Increased immunoreactions for Dsp protein are recognized in the coronal dentinal tubules and dental pulp (c, e), and intense expression of Dsp mRNA appears in some cementoblasts (j, I). B: bone, CB: cementoblasts, D: dentin, DP: dental pulp, JE: junction epithelium, OB: odontoblasts, PDL: periodontal ligament, rOB: resting odontoblasts Bars $250 \mu \mathrm{m}(\mathrm{a}, \mathrm{c}, \mathrm{e}, \mathrm{g}), 50 \mu \mathrm{m}(\mathrm{j})$, $25 \mu \mathrm{m}(b, d, f, h, i, k, l)$

results from immunohistochemical experiments demonstrating the highly specific manner of expression of Dsp protein in developing rat molars during Days $0-17(4,10,13)$ and developing mouse incisors or molars during Day 1 to 13.5 months $(5,20$, 58). However, our immunostaining for Dsp gradual- ly increased in intensity in predentin matrix, dentinal tubules and odontoblasts, and appeared in many cells of the dental papilla or pulp. The discrepancy between the expressions of Dsp mRNA and Dsp protein could be explained from three possible perspectives. First, the antibodies may detect epitopes 
Table 3 Summary of nestin and Dsp immunoreactivity and Dsp mRNA expression in each cell type during dentinogenesis in developing molars

\begin{tabular}{|c|c|c|c|c|c|}
\hline & dental papilla & preodontoblasts & $\begin{array}{c}\text { immature } \\
\text { odontoblasts }\end{array}$ & $\begin{array}{c}\text { mature } \\
\text { odontoblasts }\end{array}$ & $\begin{array}{c}\text { resting } \\
\text { odontoblasts }\end{array}$ \\
\hline nestin & $+/-$ & + & ++ & ++ & ++ \\
\hline Dsp & $+/-$ & + & ++ & +++ & +++ \\
\hline Dsp mRNA & - & + & ++ & ++ & $+/-$ \\
\hline
\end{tabular}

for other proteins similar to Dsp that are synthesized by pulpal cells (43). Second, pulpal cells may take up Dsp protein into their cytoplasm that has been secreted by differentiating and differentiated odontoblasts. Lastly, it is probable that Dsp mRNA is expressed at undetectable levels in the pulpal cells, and subsequently Dsp protein gradually accumulates in their cytoplasm according to the progress of dentinogenesis. The last idea is supported by the findings of a recent study that demonstrated that DSPP is also expressed in lower levels in bone and nonmineralized tissue (58).

Regarding the regenerative process after tooth injuries such as cavity preparation and pulpal capping following pulp exposure, newly differentiated or surviving odontoblast-like cells express Dsp protein in addition to the immunoreaction in the tertiary dentin $(14,25)$, suggesting that this protein is a reliable marker for regenerated odontoblasts and tertiary dentin. However, immunohistochemistry for Dsp is unable to determine the up-regulation of Dsp production in the afflicted odontoblasts, because Dsp protein has already been accumulated in their cytoplasm. Analysis for Dsp mRNA is necessary for precise distinction between the accumulation of protein and up-regulation of its production. The present study demonstrated that some odontoblasts beneath the enamel-free area expressed intense Dsp mRNA at Week 8. Tertiary dentin is formed under this area according to aging (31), because this area lacking the enamel covering is directly exposed to the oral environment. Thus, the continuous irritation via the enamel-free area could induce the up-regulation of Dsp synthesis in the odontoblasts beneath this area. The intense expression of Dsp mRNA in the odontoblasts adjacent to the pulpal floor at Week 8 suggests that their secretory activity correlates with the continuous deposition of secondary dentin in this area.

\section{Nestin}

The present immunohistochemistry for nestin confirmed that nestin is valuable as a differentiation marker for odontoblasts (26). Furthermore, our double immunohistochemistry for nestin and Dsp proteins clearly demonstrated that the timing of their expressions in the odontoblast-lineage cells was synchronized: preodontoblasts began to express both proteins and increased their intensity according to the progress of odontoblast differentiation, and finally mature odontoblasts showed intense expression of both proteins in their cytoplasm. However, the immunoreaction for Dsp was accumulated in the other pulpal cells, whereas nestin was exclusively expressed in the differentiated odontoblasts in the mature dental pulp. Thus, nestin is a more reliable marker for differentiated odontoblasts compared with Dsp protein. Although the expression patterns of nestin mRNA in the dental pulp of developing and aged teeth remain to be elucidated at the present, it is assumed that nestin mRNA is consistent with nestin protein judging from the cytoskeletal characteristics of intermediate filament nestin and the facts demonstrated by the previous study focusing on the pancreatic cancer (29). Furthermore, our preliminary study has confirmed the usefulness of nestin as a marker for differentiated odontoblast-like cells even in the environment of in vitro culture (author's unpublished data). Further study is needed to clarify the exact nature of nestin as a marker for differentiated odontoblasts.

\section{Classification of odontoblast-lineage cells (Table 3)}

Based on the present results, we reconsider the terminology for classification of odontoblast-lineage cells. Preodontoblasts began to express nestin and Dsp proteins and Dsp mRNA, which increased their expression intensities according to the progress of odontoblast differentiation. Since the matrix-producing cells lack their proliferative activity and acquire a differentiation marker such as heat-shock protein 25 during odontogenesis in rats (32, 33), proliferating cells are defined as "dental papilla cells" and the polarized cells beginning to acquire their differentiation markers such as nestin and Dsp are named "preodontoblasts". Matrix-producing cells increasing 
the expression of their nestin and Dsp are referred to as odontoblasts, and these cells are further divided into subgroups. In our previous study using continuously growing rat incisor teeth, we have divided these cells into three types: immature, mature, and post-odontoblasts, according to their morphology, the rate of dentin deposition, and their nutritional supply (the location and ultrastructure of the odontoblastic capillaries) (39). The cells beginning to produce predentin are characterized by immature features including minute projections on their distal ends and are engaged in the production of mantle dentin where no capillaries are present in the odontoblast layer. These immature cells are referred to as "immature odontoblasts". Subsequently, they increase in height and develop a thick cellular process during active dentin formation resulting in the pseudostratified layer and fenestrated capillaries are always located close to the predentin. Based on their mature morphology and capacity for dentin deposition and sufficient nutritional supply, these odontoblasts can be described as "mature odontoblasts". The intense expression of Dsp mRNA in mature odontoblasts in this study was precisely correlated with their functional activity. In contrast, the term "post-odontoblasts" is not suitable for the general terminology used in the process of dentinogenesis, because their appearance is a peculiar status due to an inflammatory reaction caused by the attrition of the incisal tip (39, 50, 52). The expression of Dsp mRNA in the odontoblasts became weak in intensity at Week 5 and almost disappeared at Week 8 in this study, suggesting the existence of odontoblasts that have vacated an active synthetic phase and committed to a quiescent phase. The term "resting odontoblasts" seems suitable for the definition of these cells $(13,14)$.

In conclusion, nestin is valuable as a differentiation marker for odontoblasts, whereas Dsp mRNA is a functional marker for their secretory activity. Regarding the classification of odontoblasts, immature, mature, and resting odontoblasts are universal terminology in teeth with limited growth including human teeth from morphological and functional perspectives. Further study should continue to provide the information on the additional molecular markers that starts to be expressed in mature odontoblasts (or ceases to be expressed in immature odontoblasts) to clarify the precise distinction among different types of odontoblasts.

\section{Acknowledgements}

We are grateful to Dr. Helena H. Ritchie for providing a clone for Dsp riboprobe production and Mr. Shin-ichi Kenmotsu for his technical assistance. This work was supported in part by Grants-in-Aid for Scientific Research (B) (No. 22390341 to H.O.) and Exploratory Research (No. 20659296 to H.O.) from JSPS.

\section{REFERENCES}

1. About I, Laurent-Maquin D, Lendahl U and Mitsiadis TA (2000) Nestin expression in embryonic and adult human teeth under normal and pathological conditions. Am J Pathol 157, 287-295.

2. Alvares K, Kanwar YS and Veis A (2006) Expression and potential role of dentin phosphophoryn (DPP) in mouse embryonic tissues involved in epithelial-mesenchymal interactions and branching morphogenesis. Dev Dyn 235, 2980 2990.

3. Baba O, Qin C, Brunn JC, Jones JE, Wygant JN, McIntyre BW and Butler WT (2004) Detection of dentin sialoprotein in rat periodontium. Eur J Oral Sci 112, 163-170.

4. Baba O, Qin C, Brunn JC, Wygant JN, McIntyre BW and Butler WT (2004) Colocalization of dentin matrix protein 1 and dentin sialoprotein at late stages of rat molar development. Matrix Biol 23, 371-379.

5. Begue-Kirn C, Krebsbach PH, Bartlett JD and Butler WT (1998) Dentin sialoprotein, dentin phosphoprotein, enamelysin and ameloblastin: tooth-specific molecules that are distinctively expressed during murine dental differentiation. Eur J Oral Sci 106, 963-970.

6. Begue-Kirn C, Ruch JV, Ridall AL and Butler WT (1998) Comparative analysis of mouse DSP and DPP expression in odontoblasts, preameloblasts, and experimentally induced odontoblast-like cells. Eur J Oral Sci 106 Suppl 1, 254-259.

7. Berkovitz BKB, Holland GR and Moxham BJ (2009) Oral Anatomy, Embryology, and Histology, 4th ed., Mosby, Edinburgh, London.

8. Bleicher F, Couble ML, Farges JC, Couble P and Magloire H (1999) Sequential expression of matrix protein genes in developing rat teeth. Matrix Biol 18, 133-143.

9. Bosshardt DD and Nanci A (1997) Immunodetection of enamel- and cementum-related (bone) proteins at the enamelfree area and cervical portion of the tooth in rat molars. $J$ Bone Miner Res 12, 367-379.

10. Bronckers AL, D’Souza RN, Butler WT, Lyaruu DM, van Dijk S, Gay S and Woltgens JH (1993) Dentin sialoprotein: biosynthesis and developmental appearance in rat tooth germs in comparison with amelogenins, osteocalcin and collagen type-I. Cell Tissue Res 272, 237-247.

11. Butler WT (1998) Dentin matrix proteins. Eur J Oral Sci 106 Suppl 1, 204-210.

12. Couve E (1986) Ultrastructural changes during the life cycle of human odontoblasts. Arch Oral Biol 31, 643-651.

13. D’Souza RN, Bronckers AL, Happonen RP, Doga DA, Farach-Carson MC and Butler WT (1992) Developmental expression of a $53 \mathrm{KD}$ dentin sialoprotein in rat tooth organs. $J$ Histochem Cytochem 40, 359-366.

14. D’Souza RN, Bachman T, Baumgardner KR, Butler WT and Litz M (1995) Characterization of cellular responses involved 
in reparative dentinogenesis in rat molars. $J$ Dent Res $\mathbf{7 4}$, 702-709.

15. D’Souza RN, Cavender A, Sunavala G, Alvarez J, Ohshima T, Kulkarni AB and MacDougall M (1997) Gene expression patterns of murine dentin matrix protein 1 (Dmp1) and dentin sialophosphoprotein (DSPP) suggest distinct developmental functions in vivo. J Bone Miner Res 12, 2040-2049.

16. Fisher LW and Fedarko NS (2003) Six genes expressed in bones and teeth encode the current members of the SIBLING family of proteins. Connect Tissue Res 44 Suppl 1, 33-40.

17. George A, Sabsay B, Simonian PA and Veis A (1993) Characterization of a novel dentin matrix acidic phosphoprotein. Implications for induction of biomineralization. $\mathrm{J}$ Biol Chem 268, 12624-12630.

18. Goldberg M and Smith AJ (2004) Cells and extracellular matrices of dentin and pulp: a biological basis for repair and tissue engineering. Crit Rev Oral Biol Med 15, 13-27.

19. Hao J, Zou B, Narayanan K and George A (2004) Differential expression patterns of the dentin matrix proteins during mineralized tissue formation. Bone 34, 921-932.

20. Hao J, Ramachandran A and George A (2009) Temporal and spatial localization of the dentin matrix proteins during dentin biomineralization. J Histochem Cytochem 57, 227-237.

21. Harada H, Kettunen P, Jung HS, Mustonen T, Wang YA and Thesleff I (1999) Localization of putative stem cells in dental epithelium and their association with Notch and FGF signaling. J Cell Biol 147, 105-120.

22. Harada H, Toyono T, Toyoshima K, Yamasaki M, Itoh $\mathrm{N}$, Kato S, Sekine K and Ohuchi H (2002) FGF10 maintains stem cell compartment in developing mouse incisors. Development 129, 1533-1541.

23. Harada $\mathrm{H}$ and Ohshima $\mathrm{H}$ (2004) New perspectives on tooth development and the dental stem cell niche. Arch Histol Cytol 67, 1-11.

24. Hasegawa T, Suzuki H, Yoshie H and Ohshima H (2007) Influence of extended operation time and of occlusal force on determination of pulpal healing pattern in replanted mouse molars. Cell Tissue Res 329, 259-272.

25. Hwang YC, Hwang IN, Oh WM, Park JC, Lee DS and Son HH (2008) Influence of TGF-betal on the expression of BSP, DSP, TGF-beta1 receptor I and Smad proteins during reparative dentinogenesis. J Mol Histol 39, 153-160.

26. Ishikawa $\mathrm{Y}$, Ida-Yonemochi $\mathrm{H}$, Suzuki H, Nakakura-Ohshima $\mathrm{K}$, Jung HS, Honda MJ, Ishii Y, Watanabe $\mathrm{N}$ and Ohshima $\mathrm{H}$ (2010) Mapping of BrdU label-retaining dental pulp cells in growing teeth and their regenerative capacity after injuries. Histochem Cell Biol 134, 227-241.

27. Ishikawa $\mathrm{Y}$, Ida-Yonemochi $\mathrm{H}$, Nakakura-Ohshima $\mathrm{K}$ and Ohshima H (2012) The relationship between cell proliferation and differentiation and mapping of putative dental pulp stem/progenitor cells during mouse molar development by chasing BrdU-labeling. Cell Tissue Res 348, 95-107.

28. Kawagishi E, Nakakura-Ohshima K, Nomura S and Ohshima $\mathrm{H}$ (2006) Pulpal responses to cavity preparation in aged rat molars. Cell Tissue Res 326, 111-122.

29. Kawamoto M, Ishiwata T, Cho K, Uchida E, Korc M, Naito Z and Tajiri T (2009) Nestin expression correlates with nerve and retroperitoneal tissue invasion in pancreatic cancer. Hum Pathol 40, 189-198.

30. MacDougall M, Gu TT, Luan X, Simmons D and Chen J (1998) Identification of a novel isoform of mouse dentin matrix protein 1: spatial expression in mineralized tissues. $J$ Bone Miner Res 13, 422-431.

31. Moses KD, Butler WT and Qin C (2006) Immunohistochem- ical study of small integrin-binding ligand, N-linked glycoproteins in reactionary dentin of rat molars at different ages. Eur J Oral Sci 114, 216-222.

32. Nakasone N, Yoshie H and Ohshima H (2006) An immunohistochemical study of the expression of heat-shock protein-25 and cell proliferation in the dental pulp and enamel organ during odontogenesis in rat molars. Arch Oral Biol 51, 378-386.

33. Nakasone N, Yoshie H and Ohshima H (2006) The relationship between the termination of cell proliferation and expression of heat-shock protein-25 in the rat developing tooth germ. Eur J Oral Sci 114, 302-309.

34. Nakatomi M, Morita I, Eto K and Ota MS (2006) Sonic hedgehog signaling is important in tooth root development. $J$ Dent Res 85, 427-431.

35. Nanci A (2008) Ten Cate's Oral Histology: Development, Structure, and Function, 7th ed., Mosby, Inc., and affiliate of Elsevier Inc., St. Louis, MO.

36. Ogawa R, Saito C, Jung HS and Ohshima H (2006) Capacity of dental pulp differentiation after tooth transplantation. Cell Tissue Res 326, 715-724.

37. Ogbureke KU and Fisher LW (2004) Expression of SIBLINGs and their partner MMPs in salivary glands. J Dent Res 83, 664-670.

38. Ogbureke KU and Fisher LW (2007) SIBLING expression patterns in duct epithelia reflect the degree of metabolic activity. J Histochem Cytochem 55, 403-409.

39. Ohshima H and Yoshida S (1992) The relationship between odontoblasts and pulp capillaries in the process of enameland cementum-related dentin formation in rat incisors. Cell Tissue Res 268, 51-63.

40. Ohshima H, Nakasone N, Hashimoto E, Sakai H, NakakuraOhshima K and Harada H (2005) The eternal tooth germ is formed at the apical end of continuously growing teeth. Arch Oral Biol 50, 153-157.

41. Qin C, Brunn JC, Cadena E, Ridall A, Tsujigiwa H, Nagatsuka $\mathrm{H}$, Nagai N and Butler WT (2002) The expression of dentin sialophosphoprotein gene in bone. J Dent Res 81, 392-394.

42. Qin C, Brunn JC, Cadena E, Ridall A and Butler WT (2003) Dentin sialoprotein in bone and dentin sialophosphoprotein gene expressed by osteoblasts. Connect Tissue Res 44 Suppl 1, 179-183.

43. Ritchie HH, Shigeyama Y, Somerman MJ and Butler WT (1996) Partial cDNA sequencing of mouse dentine sialoprotein and detection of its specific expression by odontoblasts. Arch Oral Biol 41, 571-575.

44. Ritchie HH, Berry JE, Somerman MJ, Hanks CT, Bronckers AL, Hotton D, Papagerakis P, Berdal A and Butler WT (1997) Dentin sialoprotein (DSP) transcripts: developmentally-sustained expression in odontoblasts and transient expression in pre-ameloblasts. Eur J Oral Sci 105, 405-413.

45. Ruch JV, Lesot H and Begue-Kirn C (1995) Odontoblast differentiation. Int J Dev Biol 39, 51-68.

46. Saito K, Nakatomi M, Ida-Yonemochi H, Kenmotsu SI and Ohshima H (2011) The Expression of GM-CSF and osteopontin in immunocompetent cells precedes the odontoblast differentiation following allogenic tooth transplantation in mice. J Histochem Cytochem 59, 518-529.

47. Shibata Y, Fujita S, Takahashi H, Yamaguchi A and Koji T (2000) Assessment of decalcifying protocols for detection of specific RNA by non-radioactive in situ hybridization in calcified tissues. Histochem Cell Biol 113, 153-159.

48. Smith CE and Warshawsky H (1975) Cellular renewal in the enamel organ and the odontoblast layer of the rat incisor as 
followed by radioautography using ${ }^{3} \mathrm{H}$-thymidine. Anat Rec 183, 523-561.

49. Suzuki S, Sreenath T, Haruyama N, Honeycutt C, Terse A, Cho A, Kohler T, Muller R, Goldberg M and Kulkarni AB (2009) Dentin sialoprotein and dentin phosphoprotein have distinct roles in dentin mineralization. Matrix Biol 28, 221229.

50. Tabata S and Semba T (1990) The odontoblasts and the blood capillaries in the incisal region of rat incisor pulp. Jpn J Oral Biol 16, 226-237. (in Japanese)

51. Takuma S and Nagai N (1971) Ultrastructure of rat odontoblasts in various stages of their development and maturation. Arch Oral Biol 16, 993-1011.

52. Takuma S (1974) Microstructure of anterior extremity of the rat incisor. Shikwa Gakuho 74, 1651-1676. (in Japanese)

53. Terasawa M, Shimokawa R, Terashima T, Ohya K, Takagi Y and Shimokawa $\mathrm{H}$ (2004) Expression of dentin matrix protein 1 (DMP1) in nonmineralized tissues. $J$ Bone Miner Metab 22, 430-438.
54. Terling C, Rass A, Mitsiadis TA, Fried K, Lendahl U and Wroblewski J (1995) Expression of the intermediate filament nestin during rodent tooth development. Int J Dev Biol 39, 947-956.

55. Yamakoshi Y (2008) Dentin sialophophoprotein (DSPP) and dentin. J Oral Biosci 50, 33-44.

56. Yokohama-Tamaki T, Ohshima H, Fujiwara N, Takada Y, Ichimori Y, Wakisaka S, Ohuchi H and Harada H (2006) Cessation of Fgf10 signaling, resulting in a defective dental epithelial stem cell compartment, leads to the transition from crown to root formation. Development 133, 1359-1366.

57. Yoshida S and Ohshima H (1996) Distribution and organization of peripheral capillaries in dental pulp and their relationship to odontoblasts. Anat Rec 245, 313-326.

58. Yuan G, Wang Y, Gluhak-Heinrich J, Yang G, Chen L, Li T, Wu LA, Chen Z, MacDougall M and Chen S (2009) Tissuespecific expression of dentin sialophosphoprotein (DSPP) and its polymorphisms in mouse tissues. Cell Biol Int 33, 816829. 